\title{
A rare presentation of prostate adenocarcinoma
}

Keywords: prostate adenocarcinoma, mandibular body, luteinizing hormone releasing hormone, lymphadenopathy, gnathic bones

\section{Introduction}

Prostate Adenocarcinoma represents the most frequent neoplasm in males corresponding to $40 \%$ of the cases and being the second cause of death due to malignant tumors in men. The most frequent site for bone metastasis generally vertebral column, shoulder joints and sacro-iliac bones. Bone metastases to mandible are extremely rare and represent only $1 \%$ of all malignant mouth neoplasms. Due to the existence despite the rare occurrence, we would like to present this case and discuss the diagnosis, management and prognosis for such patient.

\section{Case report}

A 60 years old gentleman was referred to us in February 2015 with acute retention of urine. He was admitted to another hospital 5 days ago with the same problem he was treated with catheterization and failed trial without catheter after 3 days with alpha- blockers. Clinically he was cachectic and had a large, hard and non-tender swelling over his left lower jaw as shown in Figure $1 \&$ Figure 2. There were no palpable cervical lymph nodes. Abdominal and Neurological examinations were unremarkable. Digital rectal examination revealed an enlarged T4 prostate cancer. Prostate Specific Antigen (PSA) was $100 \mathrm{ng} / \mathrm{ml}$. CT of Mandible showed a large destructive lytic lesion mass over the body of mandible reaching both buccal and lingual cortices and less pronounced lucency within the mandibular body with breech of buccal surface (Figure 3). CT chest showed sclerotic metastases throughout bony cavity with multiple pulmonary metastases (Figure 4). CT abdomen showed a markedly enlarged prostate gland (Figure 5) with secondary hypertrophy of the bladder wall, bilateral iliac lymphadenopathy measuring up to $3 \mathrm{~cm}$ and diffuses sclerotic metastases throughout the bony skeleton. Other solid organs are unremarkable.

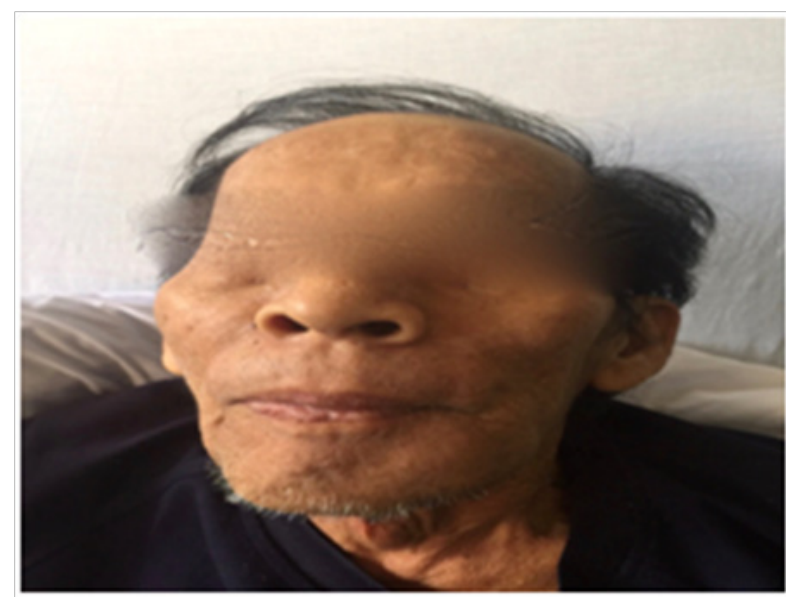

Figure I Swelling left mandible.
Volume 6 Issue I - 2018

\author{
Altawil S,' Ibrahim Z,' Sani N,' Aung P,' \\ Bhatti S,' Telesinghe ${ }^{2}$ \\ Urology Unit, RIPAS Hospital, Brune \\ 2Pathology Department, RIPAS Hospital, Brune
}

Correspondence: Samer Altawil, Urology Unit, RIPAS Hospital, Bandar Seri Begawan, Brune,

Email the lord2002@hotmail.com

Received: November 23, 2017 | Published: January 10, 2018

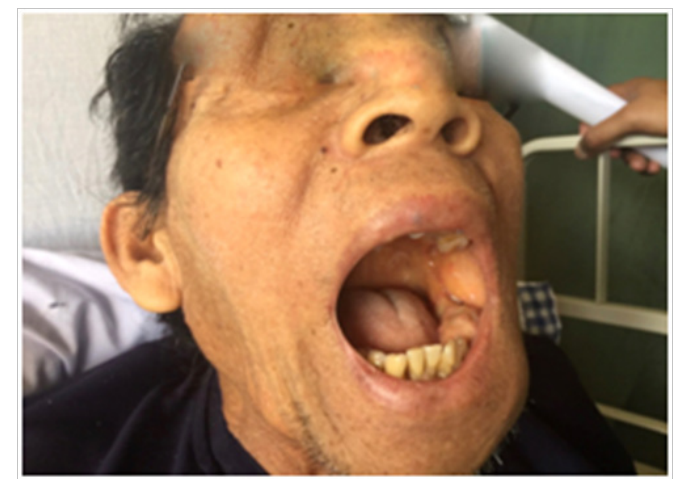

Figure 2 Left mandibular swelling inner view.

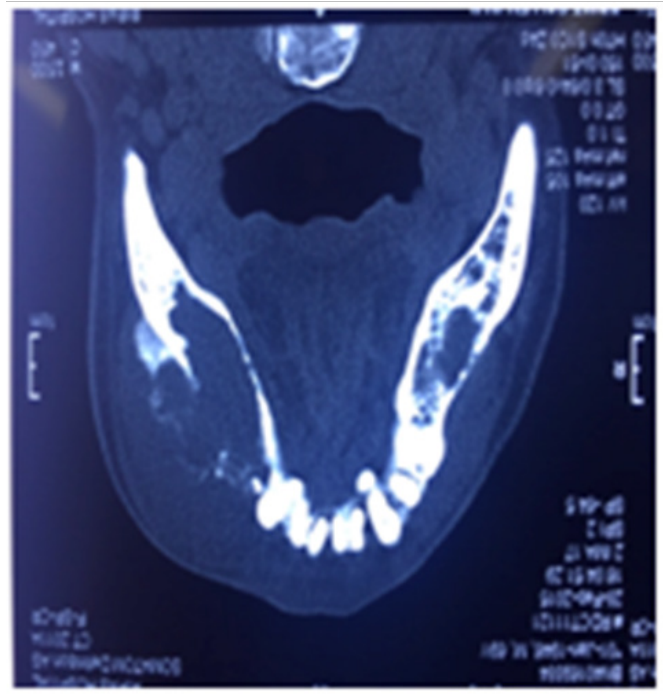

Figure $3 \mathrm{CT}$ of Mandible showing Buccal surface. 


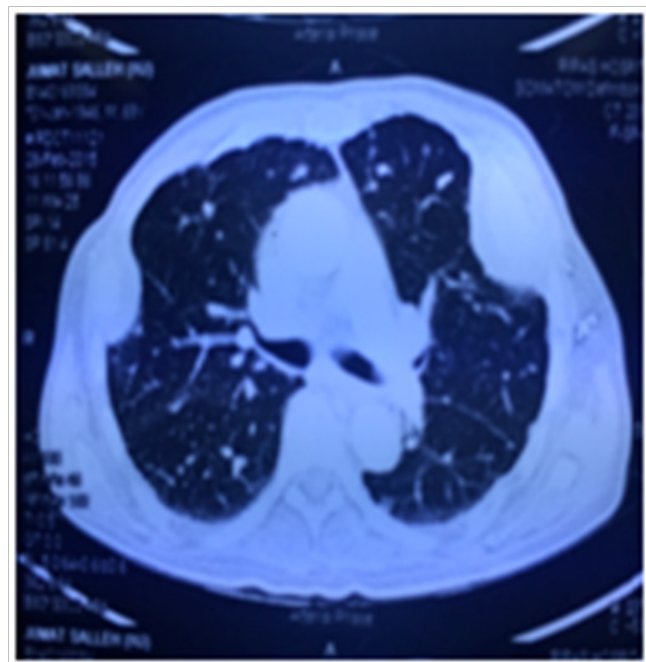

Figure $4 \mathrm{CT}$ chest showing sclerotic metastases.

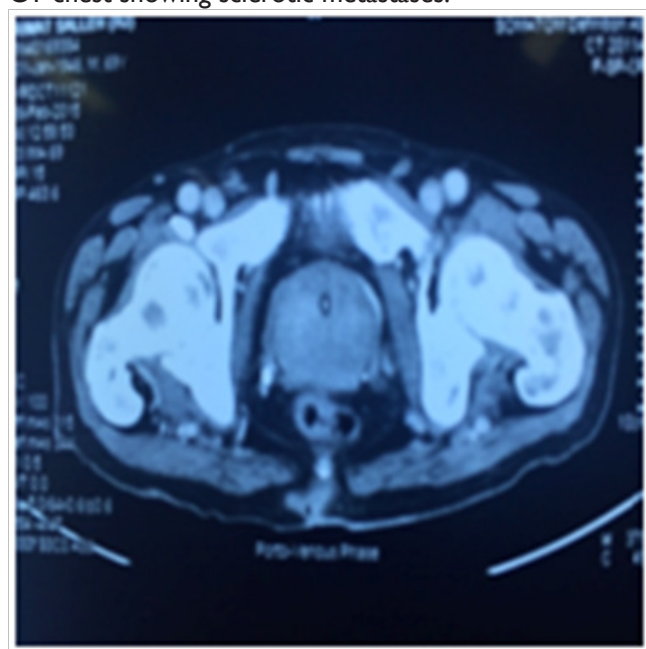

Figure 5 Enlarged prostate gland.

Trans-rectal ultrasound guided biopsy of the prostate confirmed the adenocarcinoma Gleason score $9(4+5)$, while the mandibular lesion biopsy revealed metastatic prostate adenocarcinoma (Figures 6-8).

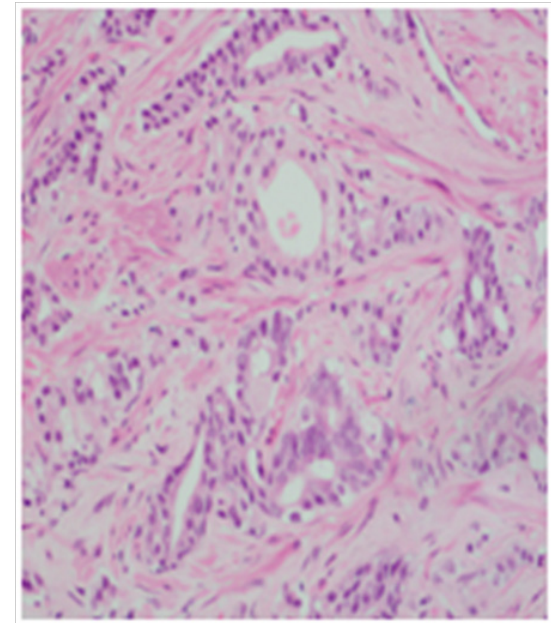

Figure 6 Mandibular biopsy.
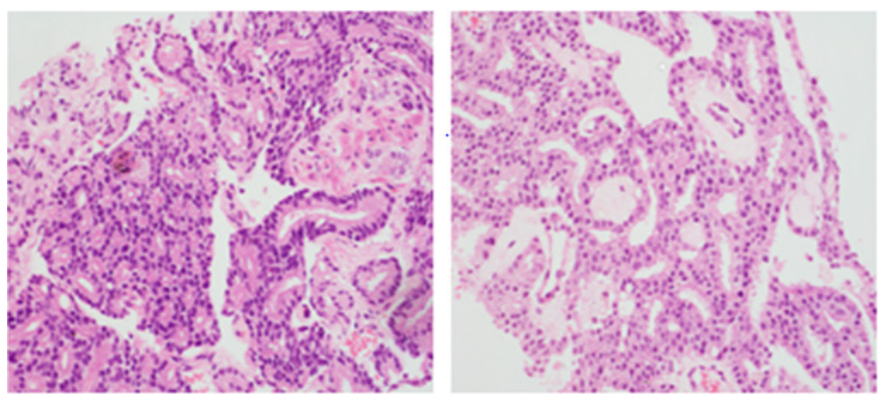

Figure 7 \& 8 Prostate biopsy.

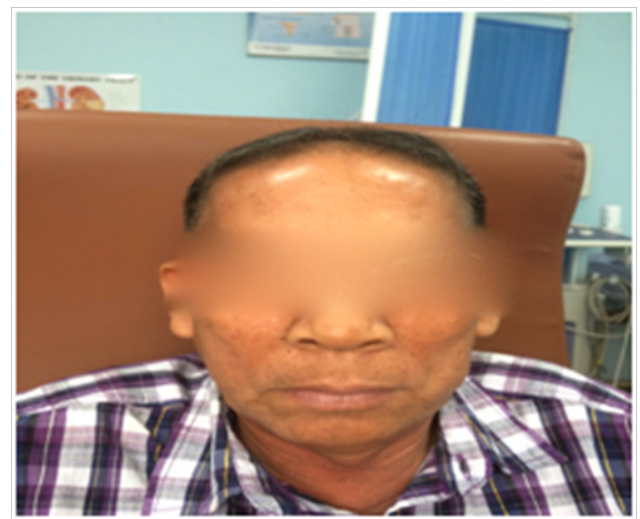

Figure 9 Patient after 18 months from the initial presentation.

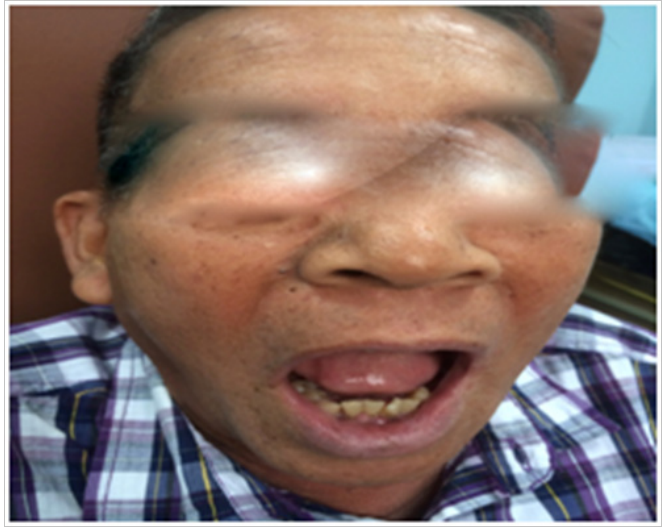

Figure 10 Patient after 18 months from the initial presentation.

As a primary 1 st line treatment of metastatic prostate cancer he received Luteinizing Hormone Releasing Hormone (LHRH) analogue injection (3.6 mg once a month through subcutaneous route) with anti androgens (Bicalutamide) in addition to alpha blocker (alfuzocine) for the prostate enlargement and calcium supplements for bones in metastatic disease. His urinary catheter was removed after 4 weeks; his PSA reduced to 16 and his mandibular swelling was reduced. After 6 months of the same treatment the patient have no urinary complains, his PSA is 1 and with resolved swelling over the left lower jaw. Figure $9 \&$ Figure 10 shows the patient during his recent clinic review, 18 months after the initial presentation.

\section{Discussion}

Involvement of the jaw in prostate adenocarcinoma is rare. Rutsatz et al. ${ }^{1}$ in a period of 35 years, reported 1008 patients with craniofacial malignancies, found only five patients $(0.5 \%)$ with metastatic tumors to the jaw, from different primary sites. Piattelli et al. ${ }^{2}$ conducted 
a survey of 390 oral cancer cases, of which 22 cases (5.6\%) were metastatic tumors on gnathic bones from other regions, being prostate gland the primary site of these tumors, as occurred in our case. ${ }^{2}$ Although rare, prostate carcinoma can metastasize to mandible. The study of Clausen \& Poulsen ${ }^{3}$ indicates that prostatic carcinoma is the primary source of more than $6 \%$ of metastatic lesions of the mandible, and a review of the literature by Vrebos et al. ${ }^{4}$ revealed that $5 \%$ of the malignant lesions metastatic to the jaws were from the prostate gland. In a study of Daley et al. ${ }^{5}$ which evaluated 38 cases of metastatic disease, prostate carcinoma was found to be the most common primary site $(21 \%)$ for oral metastases. Van der Waal and colleagues reported similar rates of $12 \%$ prostatic cancers in 24 cases.

The most common site of primary tumor that lead to metastases to the jaw are breast $42 \%$, lungs $22 \%$, bone $9 \%$, adrenal $8.5 \%$, female genital organs $7 \%$ and thyroid $6 \%$. Differential diagnoses include pyogenic granuloma, giant cell granuloma, ossifying fibroma, osteomyelitis and temporo-mandibular joint diseases. Mandibular metastases frequently occur in the premolar and molar areas. The main clinical manifestations include pain, swelling, tooth loss, bleeding, trismus and paresthesia. Symptoms associated with metastases are pain, facial swelling, intraoral mass, teeth mobility, gingival irritation, halitosis, trismus and numb chin syndrome (NCS) ${ }^{6,7}$ Diagnosis is made on histopathology grounds; in few cases it's difficult to identify the primary site. Two most common Cytokeratine (CK) stains CK7 and CK 20 and their combination are used. ${ }^{8}$ In adenocarcinoma CK7 and 20 are negative. Recently Alpha Methyl Acyl Coenzyme A Racemase (AMACR) is used to identify poorly differentiated prostate cancers primary with more accuracy, ${ }^{9}$ but it's not available in our laboratory. We used PSA test for the tissue from metastatic site to diagnosed metastasis from prostate.

\section{Conclusion}

In our case prostate adenocarcinoma was the cause. Identification could only be made by histo-pathological analysis. Despite the rare occurrence, the clinicians especially who deals with oncology patients should have high index of suspicious prostate adenocarcinoma in elderly male with mandibular swelling, facial pain and numbness.
The Mainstay of treatment is Hormonal therapy and palliative radiotherapy.

\section{Funding}

None.

\section{Acknowledgements}

None.

\section{Conflicts of interest}

None.

\section{References}

1. Sandler HM, Eisenberger MA. Assessing and treating patients with increasing prostate specific antigen following radical prostatectomy. $J$ Urol. 2007;178(3):S20-S24.

2. Piattelli A, Fioroni M, Rubini C. Gingival metastasis from a prostate adenocarcinoma: report of a case. J Periodontol. 1999;70(4):441-444.

3. Clausen F, Poulsen H. Metastatic carcinoma of the jaws. Acta Pathol Microbiol Scand. 1963;57:361-374.

4. Vrebos J, Masson J, Harrison EJ. Metastatic carcinoma of the mandible with primary tumor in the lung. Am J Surg. 1961;102: 52-57.

5. Daley T, Darling MR. Metastases to the mouth and jaws: a contemporary canadian experience. J Can Dent Assoc. 2011;77: b67.

6. Glaser C, Lang S, Pruckmayer M, et al. Clinical manifestations and diagnostic approach to metastatic cancer of the mandible. Int J Oral Maxillofac Surg. 1997;26:365-368.

7. Dib LL, Soares AL, Sandoval RL, et al. Breast metastasis around dental implants: a case report. Clin Implant Dent Relat Res. 2007;9(2):112-115.

8. Varadhachary GR, Abbruzzese JL, Lenzi R. Diagnostic strategies for unknown primary cancer. Cancer. 2004;100:1776-1785.

9. Cho JY, Shim EJ, Kim IS, et al. Cancer of unknown primary finally revealed to be a metastatic prostate cancer: a case report. Cancer Res Treat. 2009;41:45-49. 